\title{
Type 2 Antifolates in the Chemotherapy of falciparum Malaria
}

\author{
Reinaldo T. Delfino, Osvaldo A. Santos-Filho ${ }^{\#}$ and José D. Figueroa-Villar* \\ Departamento de Química, Instituto Militar de Engenharia, Praça General Tibúrcio, 80, Praia Vermelha, \\ 22290-270 Rio de Janeiro - RJ, Brazil
}

\begin{abstract}
Cerca de $40 \%$ da população mundial está exposta à malária, o que resulta na morte de mais de dois milhões de pessoas por ano na África, América Latina, Ásia Meridional e Oceania. A forma mais grave de malária em humanos é causada pelo protozoário Plasmodium falciparum. A quimioterapia ainda é uma das principais estratégias de controle deste parasita. Muitos dos antimalariais atuam inibindo a enzima di-hidrofolato redutase (DHFR), o que resulta na morte do protozoário. Contudo, o desenvolvimento de resistência tem reduzido a eficiência dos antifolatos como antimalariais. Este fenômeno foi relacionado à ocorrência de mutações na di-hidrofolato redutase do parasita. Este artigo faz uma revisão rapida de algumas características da malária falciparum, seguida de uma revisão extensiva da di-hidrofolato redutase do $P$.falciparum e das mutações relacionadas à resistência a antifolatos.
\end{abstract}

About $40 \%$ of the world population is exposed to malaria, which results in the death of over 2 million people per year in Africa, Latin America, Southern Asia and Oceania. The most severe type of malaria in humans is caused by the protozoan parasite Plasmodium falciparum. Chemotherapy is still one of the main control strategies for this parasite. Many of the antimalarials act by inhibiting the enzyme dihydrofolate reductase (DHFR), resulting in protozoan death. However, the development of drug resistance is reducing the efficiency of antifolates as antimalarials. This phenomenon has been linked to the occurrence of mutations in the dihydrofolate reductase of the parasite. This article includes a preliminary review of some of the features of falciparum malaria, followed by a more extensive review of the dihydrofolate reductase of $P$. falciparum and the mutations related to antifolate resistance.

Keywords: malaria, Plasmodium falciparum, dihydrofolate reductase, antifolate resistance

\section{Introduction}

Nowadays, a significant part of the world population is exposed to diseases caused by protozoan parasites. There are approximately 10,000 known protozoan species, which cause more human parasitic infections than any other type of organism. ${ }^{1}$ The major protozoan diseases, which affect mainly developing countries, are malaria, trypanosomiasis, leishmaniosis and toxoplasmosis. ${ }^{2}$ Although found all over the world, these diseases are most common in tropical countries, where high levels of malnutrition, poor health education and the lack of basic sanitation are associated with adequate climates for the proliferation of the vectors.

*e-mail: d5figuer@epq.ime.eb.br

\# Present Address: Laboratory of Molecular Modeling and Design, Department of Medicinal Chemistry and Pharmacognosy (M/C 781), College of Pharmacy, The University of Illinois at Chicago, 833 South Wood Street, Chicago, IL 60612-7231
Malaria is, perhaps, the most dangerous protozoan disease. It affects about 300 million people around the world, causing between 1,000,000 and 1,500,000 deaths annually. ${ }^{3}$ Children under 5 years old correspond to a large fraction of these fatalities, as malaria kills an African child every 30 seconds. ${ }^{4}$ It is estimated that more than 2 billion people (approximately $40 \%$ of the world population) are living in regions exposed to malaria infection. ${ }^{4}$ Most of the cases of the disease are registered in tropical Africa, though it is also common in large areas of Latin America, Southern Asia and Oceania. ${ }^{3}$

There are some pharmaceuticals that can be employed in malaria treatment. Generally, they explore metabolic differences between the parasite and the host, using certain enzymes as targets. ${ }^{5}$ However, there are several evidences indicating that these drugs have been loosing their efficacy along the last decades, in most cases due to the occurrence of mutations in the primary structure of the targeted parasite enzyme. For this reason, the development of new drugs 
that are effective against the wild and the mutant strains of the parasite is imperative. Unfortunately, the multinational pharmaceutical companies do not have a significant interest in researching new antimalarials. The creation and development of a new drug is a process with high costs and an enormous economic risk, and these companies consider that the risks of developing new antimalarials outweigh the expected profits. ${ }^{6}$ This phenomenon has always occurred, and most of the antimalarials in common use today were discovered by researchers outside the pharmaceutical industry. In this way, the development of new antimalarials has been relatively slow, despite the important contributions made by the public sector.

The dihydrofolate reductase (DHFR) domain of Plasmodium falciparum bifunctional enzyme dihydrofolate reductase - thymidylate synthase (DHFR TS) is one of the few well defined targets in the chemotherapy of malaria. ${ }^{7}$ The focus of this review will be the falciparum malaria (the most severe form of the disease), the $P$. falciparum DHFR (the target for a class of antimalarials known as type 2 antifolates), the mutations related to antifolate resistance and the theoretical models constructed with molecular modeling in attempt to understand the mechanisms of this resistance.

\section{Malaria}

\subsection{Disease description}

As already mentioned, malaria is an endemic disease in several regions of Africa, Latin America, Asia and Oceania. It can cause anemia, pulmonary edema, renal failure, jaundice, shock and cerebral complications. If not treated in a timely and adequate manner, it can result in death. ${ }^{1}$ Malaria is caused by protozoan species from the genus Plasmodium, which are transmitted by infected females of Anopheles mosquitoes. Only four species of Plasmodium cause the disease in humans: P. falciparum, $P$. vivax, $P$. ovale and $P$. malariae ${ }^{4,6}$ It is usual to nominate malarial infections according to the species of the parasite involved. It is worthy of note that concurrent infections by more than one species are found in regions where malaria is endemic; these multiple infections further complicate patient management and the choice of treatment regimens. ${ }^{1}$

Falciparum malaria has an incubation period (the time elapsed from the mosquito bite to the appearance of clinical symptoms) of 1 to 3 weeks (average of 12 days). It is the most severe type of the disease, being responsible for a considerable number of lethal cases. It is believed that its pathogenicity results from its rapid rate of asexual reproduction in the host and its ability to sequester in small blood vessels, ${ }^{6}$ as well as its capacity to utilize erythrocytes of all ages for reproduction.

The dissemination of falciparum malaria occurs mainly in tropical Africa, where most people are infected during childhood. As a consequence, most morbidity and mortality are observed in children under five years old. Most children that survive gradually develop a type of "partial immunity", which protects them from the severe form of the disease. ${ }^{4,6}$ Even so, a small proportion (but still a numerically large group) develops severe malaria, causing one million deaths annually. ${ }^{6}$ Morbidity and mortality are also seen in "partially immune" young women, who are at risk from severe anemia during pregnancy (especially the first one). On the other hand, in South America, Southeast Asia, India and China, falciparum malaria is less common than in Africa. Because of its low (and usually seasonal) transmission rates, partial immunity does not develop so readily, and all age groups could be affected by the severe form of the disease. ${ }^{6}$

In Brazil, the spreading human activities in the Amazon Region has caused an increase in the number of registered cases of malaria, due to the excellent climatic conditions of this region for vector proliferation, as well as the lack of adequate vector control planning and infrastructure. Consequently, more than $99 \%$ of the cases of malaria in Brazil are registered in the Amazon Region. There are 54 species of Anopheles mosquitoes in Brazil; 33 of which are found in the Amazonia. ${ }^{8}$ Of these vectors, A. darlingi is the main malaria vector in the country. This mosquito species is the most antropophilic of all, being capable of maintaining endemic levels of the disease, even when its populational density is low. ${ }^{9}$ As an average, at the beginning of the 1990's, there were 450,000 registered cases of malaria in Brazil annually (77.2\% of vivax malaria and $21.8 \%$ of falciparum malaria), causing 10,000 deaths per year. ${ }^{10}$

Up to date, the creation of an effective vaccine against malaria has not been possible. Vaccines can prevent several infections by viruses and bacteria, microorganisms that generally can be easily cultivated in vitro and have relatively simple life cycles. ${ }^{11}$ For these reasons, vaccines against viral and bacterial infections usually can be developed in a simpler way, although there are many exceptions to this rule. On the other hand, the difficulty of generating large amounts of Plasmodium parasites in in vitro cultures and the complexity of their life cycle, which includes several morphologically and antigenically different parasite forms, have hampered the development of a malaria vaccine. To be efficient, this vaccine should be a complex mixture of antigens expressed at different stages of the Plasmodium life cycle. ${ }^{11}$ Even more, there are other serious obstacles to be overcome in order to create an 
adequate vaccine against malaria, including the difficulty and expense of human trials. ${ }^{12}$ As a consequence, it is believed that the development of a malaria vaccine will take a relatively long time, despite the various advances made in the area in the last years. Extensive reviews on the difficulties in developing a malaria vaccine and how they have been faced may be found in literature. ${ }^{11-13}$

While an efficient vaccine is not available, other strategies should be employed against malaria. The main strategies for controlling malaria are educational programs, chemotherapy, and vector control. This last strategy is conducted by the use of insecticides on the walls of the houses to control the vector in the dwellings, the use of insecticides to control the mosquito populations at the breeding sites and, more recently, by the use of insecticideimpregnated bed nets, especially to protect sleeping children. ${ }^{11}$ Chemotherapy will be the focus of this review.

\subsection{Chemotherapy for falciparum malaria}

Several drugs have been used in the treatment of malaria since the $17^{\text {th }}$ century. These drugs act on different stages of the malaria life cycle, although most of them target the intraerythrocytic phases of the parasite. ${ }^{14}$ It should be noted that an antimalarial could be effective against one Plasmodium species and completely ineffective against the others, thus making the use of combinations of drugs an advisable strategy for malaria chemotherapy.

According to the classification proposed by Olliaro, ${ }^{14}$ antimalarial drugs can be divided in two groups: the nucleic acid inhibitors (which we rename as nucleic acid biosynthesis inhibitors, which we believe is a more precise name) and the blood schizonticides. The nucleic acid biosynthesis inhibitors are atovaquone and the compounds known as antifolates; while the blood schizonticides can be further divided in quinoline-type and artemisinin-type compounds. Antifolates act on enzymes of the so-called folate cycle and, since they are the main interest of this review, they will be discussed in more detail later.

Atovaquone \{2-[trans-4-(4'-chlorophenyl)cyclohexil]-3hydroxy-1,4-naphtoquinone is used for both the treatment and the prevention of malaria, in combination with proguanil (a prodrug metabolically converted to cycloguanyl, an antifolate). ${ }^{6,14}$ Although the mechanism of atovaquone action and of its synergy with proguanil are not completely understood yet, it is known that it acts primarily on the mitochondrial functions of the parasite. ${ }^{14}$ When atovaquone is employed alone, the parasite rapidly develops drug resistance, making its use in combination with proguanil necessary. Despite its high efficiency, the production of this combination (commercially known as Malarone) in industrial scale is very expensive, thus making it inaccessible for most countries where malaria is a serious public health problem. Prospects for the future of Malarone are uncertain, due to its high cost and to the lack of studies on resistance development by the parasite. However, there are studies which indicate the use atovaquone with 5-fluoroorotate, as a promising combination for malaria treatment. ${ }^{15}$

On the other hand, blood schizonticides are drugs that act on the intra-erytrhocytic phases of the life cycle of $P$. falciparum, possibly targeting the parasite food vacuole..$^{14}$ The quinoline-containing schizonticides are classified in type-1 (weak bases, diprotonated and hydrophilic at neutral $\mathrm{pH}$ ) and type -2 (weaker bases, lipid soluble at neutral $\mathrm{pH}$ ) schizonticides. Several intra- and extravacuolar mechanisms for the action of these compounds have been proposed; however their correct mechanism of action and the mechanism of resistance of Plasmodium to this kind of drugs are yet to be determined..$^{5,14}$ Some of the most common antimalarials belong to this class, such as the 4-aminoquinolines chloroquine and amodiaquine (type-1 drugs) and quinine, quinidine, mefloquine and halofantrine (type-2 drugs). It should be noticed that even though halofantrine is not a quinolinic compound, it has been classified in this group due to its probable mechanism of action, similar to that of the quinolines. Structures for these compounds are shown in Figure 1, where quinidine is actually the $(+)-$ isomer of quinine.
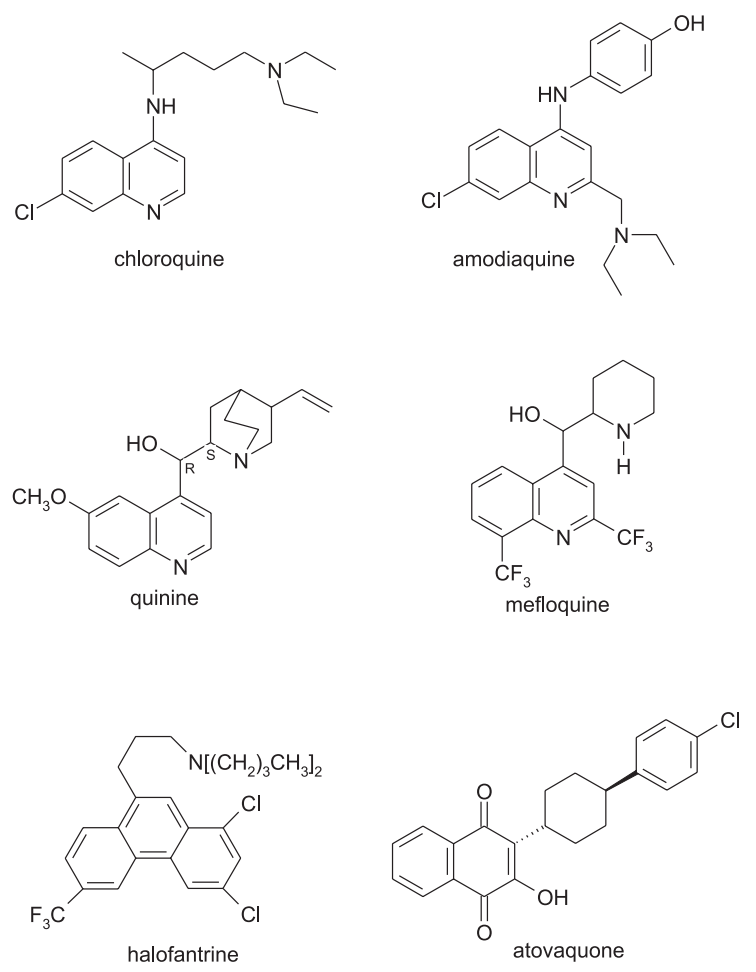

Figure 1. Structures of the main quinoline-containing drugs and of atovaquone. 
Chloroquine was the most important antimalarial drug for decades, being used for both prophylaxis and treatment of falciparum malaria. ${ }^{1}$ It is cheap, safe and adequate for outpatient use. ${ }^{6}$ Unfortunately, resistance to its action has quickly developed, and is now widespread: chloroquine can not be used anymore in Southern Asia and in many countries in Latin America. ${ }^{6,16,17}$ Chloroquine still plays an important role in the treatment of acute, uncomplicated $P$. falciparum infections in some countries where transmission is intense, notably in tropical Africa. ${ }^{15}$ Amodiaquine belongs to the same family of choroquine, but is less efficient, more expensive and more toxic. ${ }^{1,15}$

Quinine is a natural compound of relatively low potency and narrow therapeutic range, ${ }^{6}$ and was the first compound used against malaria. It was first found in a Peruvian mountain tree called chinchona, and has been used in Europe since the $17^{\text {th }}$ century. ${ }^{1}$ Resistance to quinine has been reported in Southern Asia, ${ }^{18}$ South America ${ }^{19}$ and Africa, ${ }^{20}$ but clinical failure is common only in Southern Asia, so that quinine has become the first option for treating severe falciparum malaria, especially after choroquine became unreliable. Intravenous infusion is the usual route for quinine administration, although deep intramuscular injection can be employed as an alternative route. ${ }^{6}$ Also, in some countries, like Brazil, oral administration of quinine is recommended..$^{21}$ Quinine is used as a first-line drug for malaria treatment in some temperate countries, like the United Kingdon, a practice that is less common in tropical countries. ${ }^{6}$ The $(+)$-isomer of quinine, known as quinidine, is more efficient than quinine, but it is also more toxic, being able to cause serious cardiac side effects in patients. ${ }^{1}$ Mixtures of cinchona alkaloids, known as totaquines, have also been used against malaria; standardized totaquines contain at least $15 \%$ of quinine. ${ }^{1}$

Mefloquine is a 4-quinolinemethanol structurally analogous to quinine, developed by the U.S. Army in order to replace chloroquine. ${ }^{15}$ It is used only for the treatment of uncomplicated malaria in richer countries where resistance to other drugs is widespread (like Thailand); unfortunately, it is unaffordable for general use in tropical Africa. ${ }^{6}$ Moreover, resistance to its action has been reported in some areas in Southeast Asia, mainly in the Thai borders with Burma and Cambodia. Mefloquine may be used in combination with other drugs; for example, the combination of mefloquine with artemisinin derivatives has proven to be more efficient than the former alone. ${ }^{6}$ Another used combination, known as Fansimef, involves mefloquine and the antifolates pyrimethamine and sulfadoxine. ${ }^{15}$ Rarely, mefloquine can cause serious idiosyncratic adverse reactions, while mild dose-related adverse effects, usually gastrointestinal, are common. ${ }^{1,6}$
Halofantrine is a phenanthrene-methanol derivative which has a similar spectrum of activity to mefloquine against multidrug-resistant $P$. falciparum. ${ }^{1,15}$ It is an expensive drug, whose absorption by the human organism is incomplete and variable. Halofantrine [especially the (+)-isomer] is a potentially dangerous drug, and can cause serious ventricular arrhythmias. ${ }^{6}$

Artemisinin is a sesquiterpene lactone first isolated from a wild Chinese plant (Artemisia annua) in the late 1970's, and has a potent and rapid blood schizonticidal action against Plasmodium. ${ }^{15}$ It can be used both orally and as suppositories. Some more expensive semisynthetic derivatives with greater antimalarial potency have been developed: artemether, artesunate and dihydroartemisinin (which is also the principal metabolite of artemether and artesunate). ${ }^{6}$ The structures of the artemisinin-type compounds are shown in Figure 2.

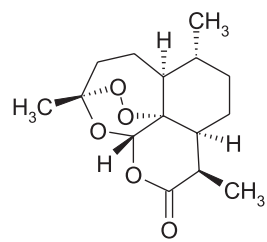

artemisinin

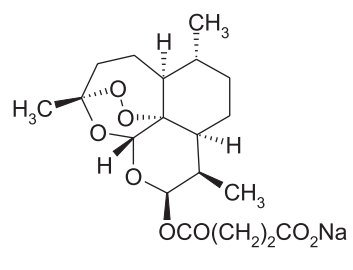

sodium artesunate

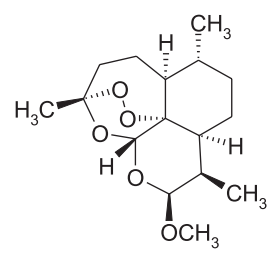

arthemeter

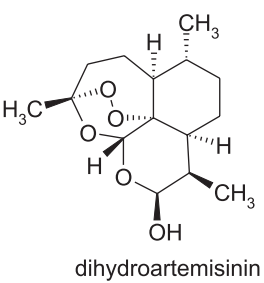

Figure 2. Structures of the artemisinin-type compounds.

The artemisinin-type compounds achieve higher reduction rates of parasitemia than any other known antimalarial, and can be used for treating uncomplicated and severe forms of malaria. All of these drugs have activity throughout the phases of the asexual intra-erythrocytic schizogonic cycle, and also act on young gametocytes. Their action is not completely understood, but the most accepted hypothesis is that reductive cleavage of the intact peroxide by ferroheme ferrous-protoporphyrin IX (Fe(II)PPIX) generates C-centred radicals which, in turn, would alkylate biomolecules, leading to the death of the parasite, as described by Olliaro. ${ }^{14} \mathrm{He}$ also states that there are not any reported cases of resistance or therapeutic failure associated to artemisinin-type drugs, although there are registered cases in the literature which suggest that 
this is no longer true. ${ }^{22}$ Anyway, the artemisinin-type compounds did not fulfill the expectations of the beginning of the 1990's, when it was hoped that they could help to reduce rapidly the mortality of severe malaria. It is believed that, at least for artemether, the drug is not well absorbed by the human organism, but this is still a matter of discussion. ${ }^{6}$

Before discussing the type 2 antifolates, we must review the target of their action: the enzyme dihydrofolate reductase.

\section{Dihydrofolate Reductase (DHFR)}

\subsection{Enzyme description}

Dihydrofolate reductase (DHFR; EC. 1.5.1.3) is an enzyme found in nearly all the living cells, with only few exceptions. Its function is to catalyze the reduction of 7,8dihydrofolate (DHF) to 5,6,7,8-tetrahydrofolate (THF), in a biochemical reaction whose coenzyme is the reduced form of nicotinamide adenine phosphate (NADPH). ${ }^{23}$

$\mathrm{DHF}+\mathrm{NADPH}+\mathrm{H}^{+} \underset{\mathrm{DHFR}}{\longrightarrow} \mathrm{THF}+\mathrm{NADP}^{+}$

Structural formulas for folate, DHF, THF and NADPH are shown in Figure 3. DHF is transformed in THF by reduction of the N5 - C6 double bond. Although the mechanism of this reaction is not fully understood, it is known that NADPH acts as an electron-donor or, more precisely, as a hydride donor, in reducing biosynthetic processes..$^{24}$ In this way, it is believed that the hydride is transferred from NADPH to the substrate $\mathrm{C} 6$ atom, while a proton is given to the N5 atom by a water molecule. ${ }^{25,26}$ Although there is not yet conclusive experimental evidence that proves that the reaction occurs in this way, this mechanism is largely accepted. ${ }^{25}$

DHFR plays an important role in the cellular metabolism of the vast majority of living creatures, since it is essential for maintenance of adequate levels of THF, which is fundamental in the metabolic cycle of biosynthesis of deoxythymidylate (dTMP), represented in Figure 4. In this cycle, thymidylate synthase (TS; EC. 2.1.1.45) catalyzes the conversion of deoxyuridylate (dUMP) and 5,10methylenetetrahydrofolate to dTMP and DHF, respectively. DHFR catalyzes the subsequent reduction of DHF to THF, a compound that is indispensable for the biochemical transference of single-carbon units. Finally, serine hydroxymethyltransferase (SHMT; EC. 2.1.2.1) catalyzes the regeneration of 5,10-methylenetetrahydrofolate, which guarantees the continuation of dTMP biosynthesis. During

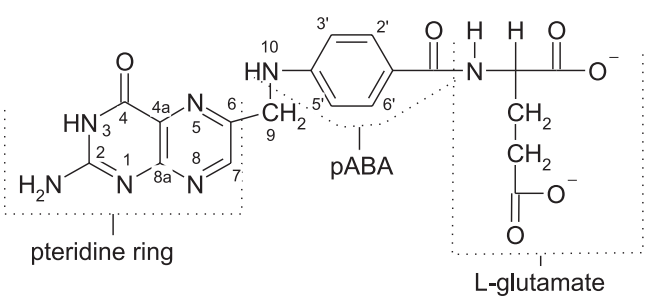

FOLATE<smiles></smiles>

DIHYDROFOLATE<smiles>[R]Cc1c[nH]c2nc(N)[nH]c(=O)c12</smiles>

TETRAHYDROFOLATE

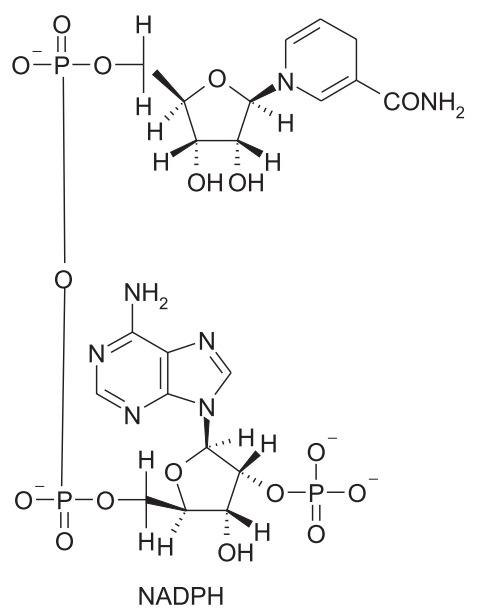

Figure 3. Structures for folate, its reduced derivatives and NADPH. The structure of folate is usually discussed in terms of the three components shown above (pABA is the p-aminobenzoyl group). In the structures of DHF and THF, R corresponds to the pABA + Lglutamate part of the folate.

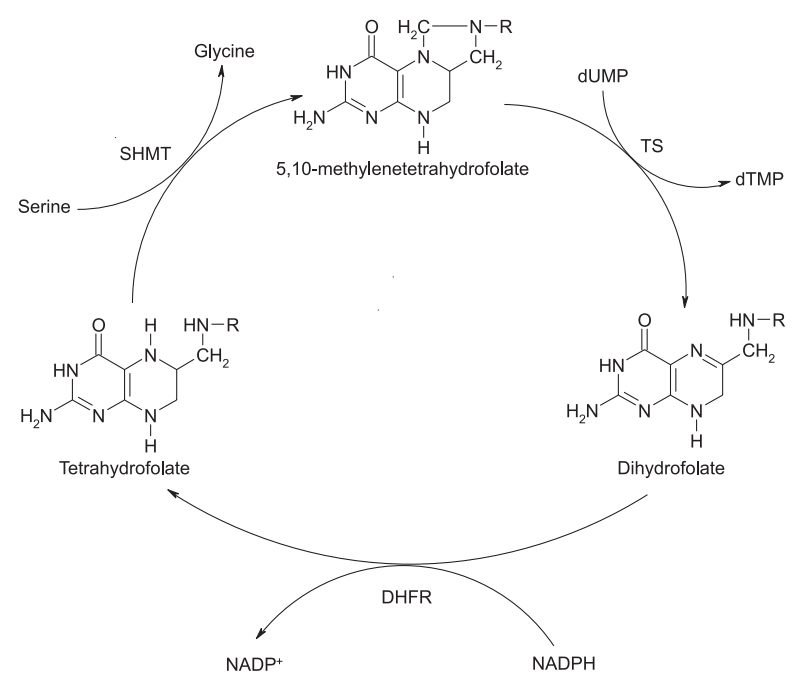

Figure 4. Biosynthetic cycle of dTMP $(\mathrm{R}=\mathrm{pABA}+\mathrm{L}$-glutamate $)$. 
the cycle, for each THF molecule oxidized to DHF, one dTMP molecule is formed. It is worthy of note that THF, in its derived forms, act as a coenzyme (transferring singlecarbon units) not only for dTMP synthesis, but also for the syntheses of purine nucleotides, methionine and other essential metabolites. Inhibition of DHFR, or of any other enzyme in the cycle prevents the formation of new dTMP molecules, which interrupts DNA synthesis. Since there is no alternative route for dTMP biosynthesis, the consequence is cellular death. ${ }^{23,27}$

Due to the close similarity between the human and the parasitic enzymes, there are not any important studies about SHMT inhibition yet, while TS inhibition has been discussed only recently. ${ }^{28}$ On the other hand, DHFR is an enzyme that has been studied for a long time. Initially, DHFR was used as a valuable tool to study the relationship between molecular structure and the functional properties of enzymes. This is convenient because, in mammals, DHFR is a relatively small enzyme (with about 200 residues, changing according to the species), thus facilitating its study by $x$-ray crystallography and NMR techniques. ${ }^{23}$ For this reason, there are several crystallographic structures of different DHFR available in the Protein Data Bank (PDB), a database with thousands of protein structures and which may be accessed by the internet (http://www.rcsb.org/pdb/). ${ }^{29}$ Unfortunately, only the primary structure of $P$. falciparum DHFR (pfDHFR) has been determined so far; ${ }^{30}$ there is no experimental information about the secondary and tertiary structures of this enzyme, due to technical difficulties for obtaining adequate quantities and concentrations for its analysis.

DHFR is also an interesting enzyme from the pharmacological point of view. It was rapidly identified as a potential target for chemotherapy, and several drugs, known as antifolates, are now used not only against malaria, but also for the treatment of other protozoan diseases, such as trypanosomiasis, leishmaniasis and toxoplasmosis, as well as other illnesses, such as bacterial infections and some types of cancer. ${ }^{23,26} \mathrm{~A}$ fundamental aspect for the use of antifolates as pharmaceuticals is the need for selectivity, thus inhibiting the parasite enzyme, and not the human enzyme. This occurs if the drug binds to the parasite DHFR with greater affinity than to the human enzyme. That is, for instance, the main deficiency of methotrexate (MTX), an antifolate used in the chemotherapy of certain types of cancer. This citotoxic compound cannot distinguish between the enzymes of healthy and neoplasic cells. Its only selectivity comes from the fact that the cancer cells, because they reproduce much more rapidly than healthy cells, are more susceptible to DHFR inhibition.

\subsection{Proposed mechanisms for DHF reduction}

As already mentioned, the mechanism of reduction of DHF to THF is not totally understood yet, although it has been extensively studied by biochemists, experimental and theoretical chemists. It is known for sure that a hydride is transferred from NADPH to carbon C6 of the substrate (Figure 3). It is also known that there is a hydrophobic pocket in the active site of DHFR, which accommodates the pteridine ring of DHF. This pocket has, at one end, a methyl group, which belongs to Thr-45 in Lactobacillus casei, Thr-46 in Escherichia coli, Thr-57 in humans and Thr/Ser/Asn-108 in P. falciparum. At the opposite end of the pocket are located the carboxylic oxygens of Asp in microorganisms (Asp-26 in L. casei, Asp-27 in E. coli and Asp-54 in P. falciparum) and Glu in vertebrates. Available crystallographic structures of bacterial and vertebrate DHFR show that the pABA + L-glutamate part of DHF (see Figure 3 ) is approximately perpendicular to the plane of the pteridine ring in the active site, which is possible due to a torsion around the methylene group that connects those parts (atom C9 in Figure 3). The 2-amino group and nitrogen N3 interact by hydrogen bonding with the carboxylic oxygen atoms of the conserved acidic residue (Asp or Glu) at the active site. ${ }^{31}$ From this point on, there are many uncertainties in the mechanism of reduction. Several models have been proposed, which differ mainly in two points: the state of the carboxylic group of the conserved Asp (or Glu) in the active site (neutral or ionized) and the mechanism for the protonation of nitrogen N5, which can be either direct or indirect (from the initially protonated carboxylate, with the aid of the oxygen atom bonded to atom C4). Cummins and Gready made a nice review of the literature concerning the mechanism of this reaction and a collection of the main models proposed so far. ${ }^{32}$ Those models are discussed next.

The chemistry of DHFR has two interesting aspects: the first one is that the reaction occurs only in the pteridine ring of the substrate, where there are several positions whose $\mathrm{pK}_{\mathrm{a}}$ values are accessible for protonation or deprotonation; ${ }^{32}$ the second one is that DHFR can catalyze not only DHF reduction to THF, but also, in some cases, folate reduction to DHF. Although this last reaction is physiologically less important (since it has a much lower turnover number), it is essential, due to the need of most organisms (including animals) to reduce the fully oxidized folate obtained from nutritional sources, for the de novo synthesis of DHF. In this way, the necessity for DHFR to be able to catalyze both of those reactions may have imposed specials restraints on the reduction mechanism.

Available crystallographic structures of DHF-DHFR 
complexes indicate that most of the interactions between DHF (or folate) and the active site of the enzyme are situated at the pyrimidine ring. These interactions involve a set of hydrogen bonds between the substrate, the conserved acidic residue (Asp or Glu) and some water molecules present in the active site, as shown in Figure 5, for $E$. coli DHFR. In this illustration, the conserved acidic residue (Asp-27) is represented in its ionized form, as it is usually done in the literature on DHFR. However, if atoms $\mathrm{OD} 2$ or $\mathrm{O} 4$ were protonated, the orientation of the hydrogen bonds would be different.

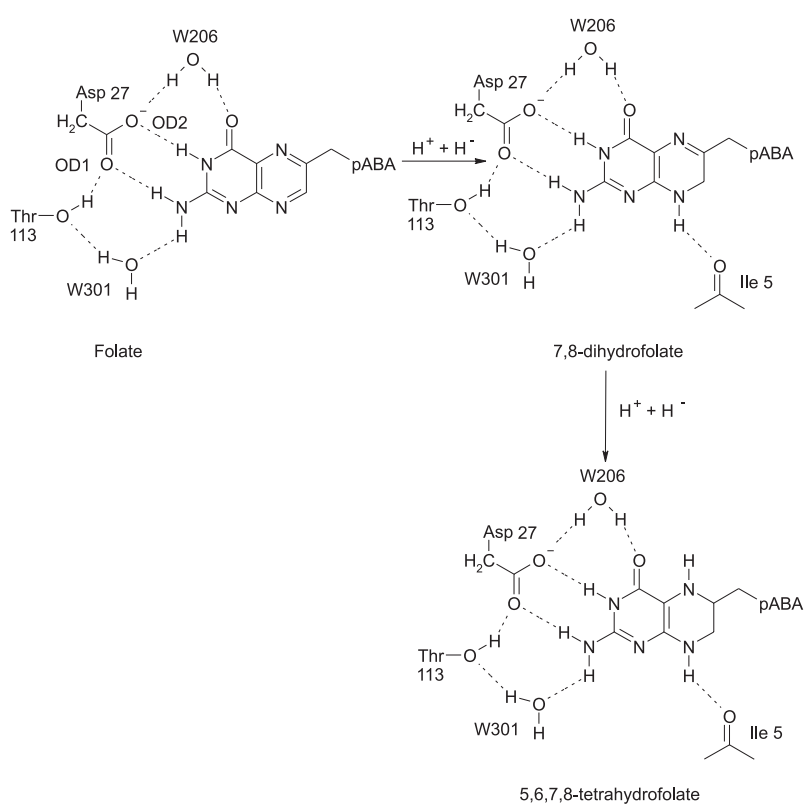

Figure 5. Reduction of folate to DHF and THF, and the set of hydrogen bonds between the substrate and E. coli DHFR active site. ${ }^{32}$

It is believed that the conserved acidic residue (Asp or Glu), which is present in all known DHFR, exerts an essential function in the catalytic mechanism, as it holds the substrate in the appropriate position for the reaction. This is accomplished by the formation of hydrogen bonds with the pteridine ring nitrogens of the substrate. However, several attempts to determine the ionization state of this acidic residue have not resulted in a definitive conclusion yet. It is believed that one conserved water molecule, which is hydrogen-bonded to atoms $\mathrm{O} 4$ and $\mathrm{OD} 2$ in the crystalline structures of DHFR complexes with DHF and NADPH, should influence the carboxylate ionization state..$^{33}$ The use of NMR and Raman spectroscopy techniques has only proven that the carboxylate group of this aminoacid is certainly ionized at $\mathrm{pH}$ values greater than five. ${ }^{32}$

Based on results obtained by kinetic, X-ray, Raman and NMR experiments, several mechanisms have been proposed for DHFR catalytic action. ${ }^{32}$ The conventional mechanism assumes that protonation of N5 occurs first, followed by the transfer of the hydride ion to carbon C6. Many models presume that the carboxylate of the conserved acidic residue should be ionized, in order to stabilize the protonated substrate. Based on $\mathrm{pK}_{\mathrm{a}}$ determinations, it has been suggested that nitrogen N5 should be directly protonated by the solvent in the active site, though the source of this proton is uncertain: the Asp/ Glu residue is the only ionizable one present in the active site of DHFR, but it is far too distant from N5, as seen in Figure 5, thus making its participation in a direct protonation of N5 unlikely. For this reason, there are mechanisms that propose, instead of a direct protonation of N5, a transitory protonation of atom O4, with an eventual solvent-aided transfer of this proton to N5. In the model proposed by Bystroff and co-workers, ${ }^{33}$ the conserved acidic residue remains protonated, and the proton added to the substrate comes from the solvent, as illustrated by Figure 6. In this mechanism, the conserved acidic residue must not be ionized in order to promote the protonation of the pteridine ring. A water molecule, which is strongly bonded to OD2 and O4 (equivalent to molecule W206 in the ternary complex of Figure 5), stabilizes the carboxylic acid of the conserved acidic residue. The mechanism consists, firstly, on the pteridine ring enolization (step c, in Figure 6), which is aided by W206 and by an additional water molecule; then, OD2 is protonated again, facilitating the transfer of a proton from O4 to N5 (d); finally, a water molecule is expelled by the closure of a flexible loop (M20 in E. coli), generating the active complex (e).

There are still other mechanisms that admit that, in the active complex, atom $\mathrm{O} 4$ is protonated. These models are based on NMR experiments carried out on DHFR complexes of $L$. casei, in which the conserved acidic residue (Asp 26) is undoubtedly ionized. ${ }^{34}$ The role of the ionized carboxylate group would be to polarize the substrate, so that the enolized form (with $\mathrm{O} 4$ protonated) would be favored over the keto-form (with N5 protonated). These mechanisms propose that the transfer of a proton from $\mathrm{O} 4$ to N5 occurs with aid of the solvent, being concerted with the transfer of the hydride. However, these models have a major deficiency: they do not explain satisfactorily the reduction of folate to DHF, since there is not a suitable way to protonate atom N8, neither by the enzyme nor by the water molecules present in active site.

From the data discussed in the previous paragraphs, one can conclude that the mechanisms for DHF reduction proposed so far differ from one another in the following aspects: $i$ ) the mechanism of $\mathrm{N} 5$ protonation (direct, or indirect with aid of O4); ii) the ionization state of the 

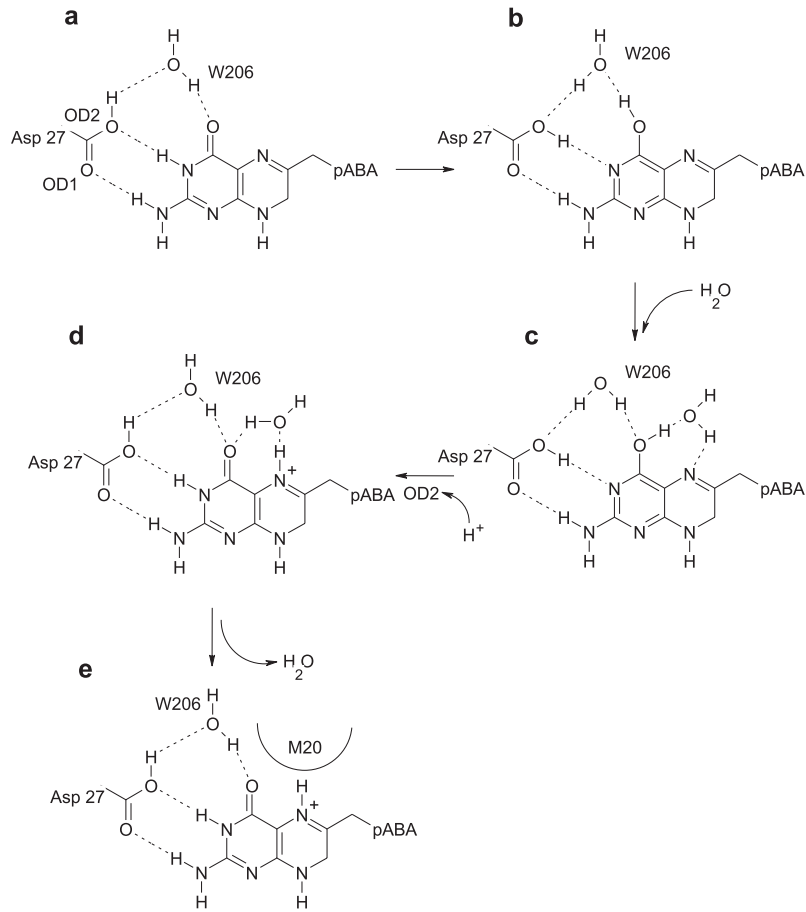

Figure 6. Catalytic mechanism for DHF reduction, proposed by Bystroff et al. from the crystalline structure of DHFR-folate-NADP ${ }^{+}$ complex. ${ }^{33,34}$

conserved acidic residue (Glu/Asp); iii) the roles of the conserved acidic residue and of the conserved water molecule (W206 in E. coli DHFR) in the catalytic mechanism; and $i v$ ) the presence or absence of a water molecule between atoms $\mathrm{O} 4$ and N5 in the active complex.

The enormous variety of suggested models for this reaction shows its high complexity. It has been even proposed that there is some kind of "non-obvious" mechanism, which is able to simultaneously explain the reductions of folate and DHF. ${ }^{32}$

\section{DHFR as Target for Malaria Chemotherapy}

\subsection{The metabolism of folate in P. falciparum}

Folate metabolism is an interesting target for the chemotherapy of parasitic diseases because it offers many possibilities for selective inhibition of biochemical processes that are vital for parasite growth. Studies on folate metabolism began more than fifty years ago, with the discovery that sulfonamides inhibit Plasmodium growth, and that $p$-aminobenzoic acid (pABA) reverts the inhibitory effects of these compounds. ${ }^{27}$ The metabolic importance of the folate cycle is in the fact that THF is a fundamental coenzyme in the synthetic metabolism of several aminoacids and nucleotides. Folate is related not only to the synthetic cycle of dTMP (Figure 4), which is essential to the biosynthesis of pyrimidinic nucleotides, but also to the synthetic cycle of methionine and to the salvage cycle of purines. ${ }^{35}$ It has been known for a long time that malarial parasites synthesize folate de novo. Recently, evidences that suggest the existence of a salvage pathway have appeared. ${ }^{27,35}$ Several enzymes usually found to participate in the de novo folate syntheses are present in protozoa of the Plasmodium genus, such as GTP cyclohydrolase, 2amino-4-hydroxi-6-hydroximethyl-dihydropteridine pyrophosphokinase (PPPK) and dihydropteroate synthase (DHPS). However, there are still some unexplained aspects in the folate metabolism of Plasmodium, since some classical enzymes of this metabolism have not been detected in parasites of this genus. For instance, dihydrofolate synthase (DHFS), an enzyme that adds glutamate to dihydropteroate to generate DHF, has never been observed in any Plasmodium. It has been shown that $P$. berghei adds $\mathrm{p}$ aminobenzoyl-glutamate to dihydropteroate forming dihydrofolate, in a direct and inefficient way. ${ }^{27}$

A hypothetical and simplified de novo biosynthetic route of folate is shown in Figure 7. It begins with the GTP cyclohydrolase-catalyzed transformation of guanosine triphosphate (GTP) into dihydroneopterin triphosphate. The latter is then successively converted to dihydroneopterin and 2-amino-4-hydroxi-6-hydroximethyl-dihydropteridin by the enzymes dihydroneopterin triphosphate pyrophosphohydrolase and dihydroneopterin aldolase, respectively (neither of these enzymes has been isolated in any parasite of the Plasmodium genus so far). 2-amino-4-hydroxi-6-hydroximethyl-dihydropteridin is transformed by PPPK into dihydropteridine pyrophosphate, which is then condensed with pABA in a DHPS-catalyzed reaction, forming 7,8-dihydropteroate. Finally, the latter is condensed with L-glutamate, in a reaction supposedly catalyzed by DHFS, generating DHF. ${ }^{27,35}$ From this point on, DHF can be transformed into

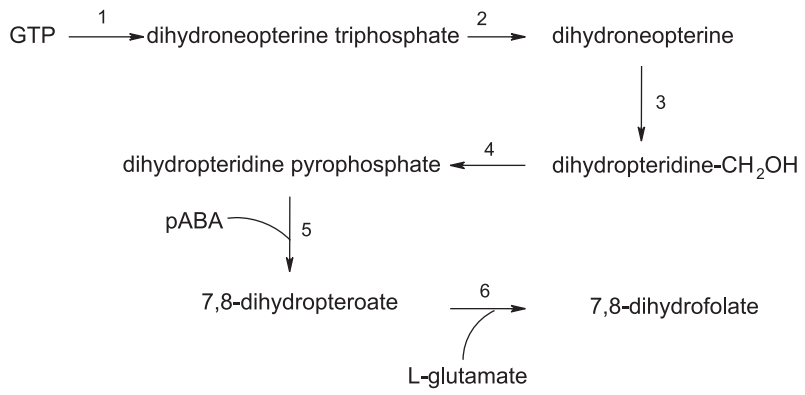

Figure 7. Hypothetical route for the de novo biosynthesis of DHF. The involved enzymes are GTP cyclohydrolase (1), dihydroneopterin triphosphate pyrophosphohydrolase (2), dihydroneopterin aldolase (3), PPPK (4), DHPS (5) and DHFS (6). 
THF by DHFR, starting the dTMP cycle, represented in Figure 4.

In P. falciparum, DHFR and TS constitute a bifunctional and dimeric enzyme, as also occurs in other protozoa such as Trypanosoma cruzi, Trypanosoma brucei and Leishmania major. ${ }^{26,27}$ The same does not occur in bacteria and mammals, where DHFR and TS are monofunctional enzymes. ${ }^{26,27}$ Bzik and coworkers determined the primary structure of $P$. falciparum DHFR-TS ${ }^{30}$ and, based on aminoacid identity and on the considerations regarding the secondary structures of other DHFR, they defined the pfDHFR domain as being constituted by residues 1 to 228 . In an analogous way, the TS domain was defined as formed by residues 323 to 608 . Residues 229 to 322 constitute a juncional sequence, with no homology with any known DHFR or TS. Actually, the primary structure of the DHFR studied by Bzik and coworkers corresponds to a mutant pfDHFR; residue 108 of wild-type enzyme is, in fact, a serine, and not an asparagine. ${ }^{36}$

So far, the experimental determination of pfDHFR-TS tertiary structure has not been possible, mainly because of technical difficulties in crystallization and in obtaining adequate concentrations of the enzyme to carry out the necessary experiments. ${ }^{27}$ Even the tertiary structure of the pfDHFR domain is unknown. However, the use of the technique known as molecular modeling by homology ${ }^{37-39}$ made possible the construction of theoretical models which permit the prevision of some structural properties of the enzyme. Four homology-constructed models of pfDHFR are available in the literature: $i$ ) the model of Lemcke and coworkers ${ }^{40}$ created from a alignment between pfDHFR and human DHFR, ; ii) the model of Rastelli and coworkers, ${ }^{7}$ which used a multiple alignment procedure with the following DHFRs as templates: E. coli, L. casei, Pneumocystis carinii, human and chicken liver; iii) the model of Santos-Filho and coworkers, ${ }^{36}$ which employed chicken liver DHFR as template; $i v$ ) the model proposed by us ${ }^{41}$ which is actually a refinement of the previous one.

In addition to these models, it should be emphasized the importance of the structural considerations made by Sirawaraporn $^{27}$ and by Warhurst ${ }^{31}$ also.

All cited models are theoretical, and should be analyzed with the due caution. However, some pfDHFR properties can be inferred from them, either because they are common to all models, or because they are present in all DHFR whose tertiary structure was crystallographically determined. Among these properties, the most important refer to the binding mode of DHF and NADPH to the enzyme. In pfDHFR, the conserved acidic residue that $\mathrm{H}$ bonds to the substrate pteridine ring is Asp-54. Although the carboxylate of this residue can rotate freely, there are evidences that suggest that ideal bonding occurs when Asp-54 and the pteridine ring of DHF are coplanar, allowing a planar bidentate bond, analogously to the case of E. coli, shown in Figure 5. ${ }^{31}$ Atoms $\mathrm{N}$ and $\mathrm{O}^{\mathrm{g}}$ of Ser-108 form a hydrogen bond to one of the phosphate groups of NADPH. There are still hydrogen bonds between Ala-16 and the carboxiamide group of the NADPH nicotinamide ring, as well as between Thr-185 and Asp-54. It is also believed that the nicotinamide ring of NADPH is close to one of the aromatic rings of DHF, allowing for the occurrence of $\mathrm{p}$ stacking or t-stacking interactions between them.

In terms of the tertiary structure, the models indicate that pfDHFR is constituted by an eight-stranded $\beta$-sheet, with seven parallel and one (the carboxi-terminal) antiparallel strand, and four or five $\alpha$-helices (varying according to the model), being the remaining of the protein composed by loops and tight turns. An example of a theoretical tertiary structure of pfDHFR is shown in Figure 8.

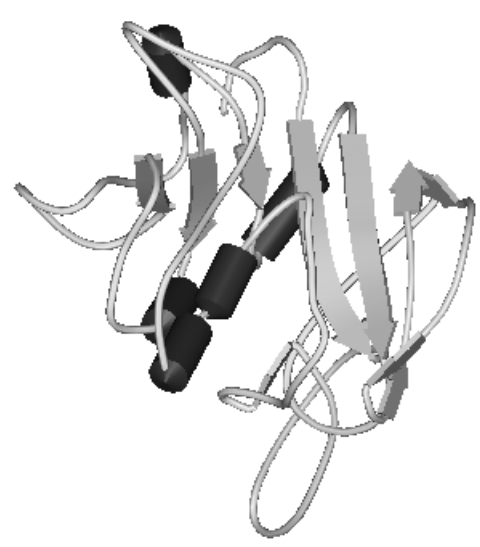

Figure 8. Tertiary structure of pfDHFR, according to a theoretical model previously proposed..$^{41}$

\subsection{Antifolates for malaria chemotherapy}

As mentioned before, antifolates, also known as folate antagonists, constitute a class of antimalarials belonging to the group of the nucleic acid biosynthesis inhibitors, according to Olliaro's classification. ${ }^{14}$ All pharmaceuticals that interfere in the folate cycle by inhibiting any of its enzymes are called antifolates. Their action results in a decrease on the synthesis rates of dTMP, purine nucleotides and metionine, among other consequences. Olliaro divided the antifolates in two groups, denominated Type 1 and Type $2 .{ }^{14}$

Type 1 antifolates are sulfones and sulfonamides whose structures are similar to pABA, with which they compete for the DHPS active site, preventing or slowing down the 
formation of 7,8-dihydropteroate, which is a precursor of DHF (see Figure 7). It is worthy of note that, in $P$. falciparum, DHPS and PPPK constitute a bifunctional enzyme, in the same way as DHFR and TS. The main Type 1 antifolates are the sulfone dapsone and the sulfonamides sulfadoxine, sulfadiazine and sulfalene, whose structures are shown in Figure 9.

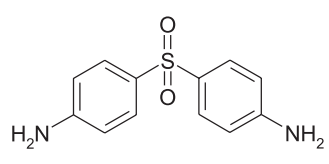

dapsone

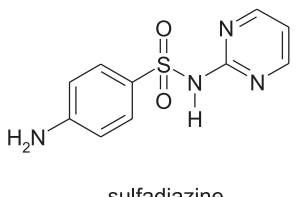

sulfadiazine

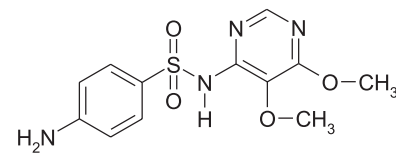

sulfadoxine

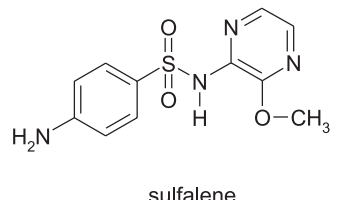

Figure 9. Structures of the main Type-1 antifolates.

The chemotherapy with Type 1 antifolates has some inconveniences. Dapsone is a very toxic drug, while the cited sulfonamides are antimalarials of easy absorption, but difficult excretion by the human organism. ${ }^{42}$ Moreover, there are strong evidences that the parasite can use efficiently exogenous folates, either as folic acid or folinic acid; this salvage pathway can bypass the blockage of the endogenous folate biosynthetic pathway induced by Type 1 antifolates. ${ }^{5}$ Finally, mutations in DHPS primary structure have been associated to an increase on the resistance of $P$. falciparum to these antifolates, mainly to sulfadoxine. The mutations in DHPS registered in the literature until the present moment are A581G, S436F, A613T, A613S, S436A, A437G and K540E. ${ }^{14,43,44}$

Type 2 antifolates are those that inhibit the parasite DHFR, preventing the DHF reduction to THF described before. These compounds are structurally similar to the pteridine ring of DHF, with which they compete for the active site of DHFR. The main Type 2 antifolates are illustrated in Figure 10.

Methotrexate (MTX) was the first DHFR inhibitor to be synthesized. It is highly toxic, mainly to the bone marrow, and resistance to its action, associated to problems in cell absorption and accumulation, has been registered..$^{28}$ Another MTX deficiency is its low selectivity: it inhibits indiscriminately human and parasite enzymes. For this reason, MTX is not suitable for malaria treatment, being used only for the chemotherapy of some types of cancer. ${ }^{26}$

Pyrimethamine (PYR) is a potent and selective inhibitor
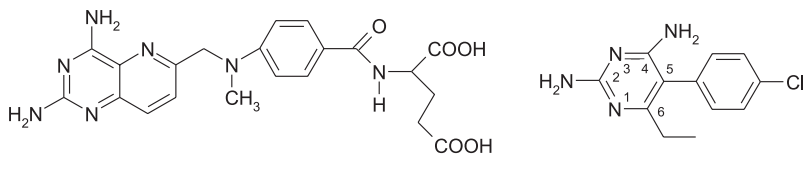

methotrexate

pyrimethamine<smiles>COc1cc(Cc2cnc(N)nc2N)cc(OC)c1OC</smiles>

trimethoprim

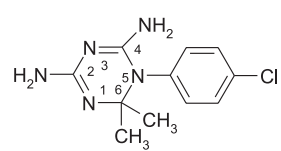

cycloguanil

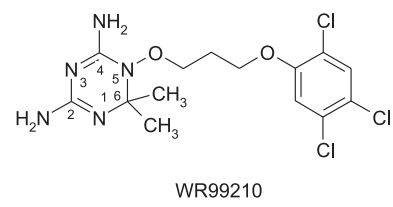

Figure 10. Structures of the main Type- 2 antifolates.

of pfDHFR, and has been used as antimalarial since 1952 . However, it acts slowly, not being indicated for the treatment of the acute phases of malaria. ${ }^{45}$ Although it can be used isolatedly, PYR is usually employed in fixed combinations with Type 1 antifolates, such as dapsone, sulfadoxine and sulfalene. ${ }^{5}$ The most used of these combinations is, undoubtedly, pyrimethamine sulfadoxine (PS), also known as Fansidar ${ }^{\mathrm{TM}}(\mathrm{ROCHE})$. PS is cheap, practical (only one dose is needed, since its elimination by the organism is slow) and highly effective in most of Africa. ${ }^{6}$ Unfortunately, it has been observed that $P$. falciparum rapidly develops resistance to PS. This phenomenon has rendered PS useless in most of South America and Southeast Asia. Even in areas where PYRresistance is not yet a problem, PS cannot be used for treating complicated malaria, since its clinical response is slow, in the same way as PYR alone.

Cycloguanil (CYC) is the metabolic product of proguanil, which was developed in Britain during World War II. It is also a potent drug with low toxicity, although slightly inferior to PYR, which is efficient in lower doses and is more slowly eliminated by the organism. ${ }^{45} \mathrm{CYC}$ can be used alone or in combination with other antimalarials, such as chloroquine or atovaquone, ${ }^{6,15}$ but its use is also affected by increasing parasite resistance.

Trimethoprim (TMP) is a drug whose action is similar to PYR. Due to its slow action, TMP is usually combined with other antimalarials with faster action, such as sulfalene. ${ }^{42}$ Although TMP can be used as antimalarial, it is most employed against bacterial infections. An important difference between TMP and PYR (or CYC) is the existence 
of a methylene group between the two aromatic rings, which confers more flexibility to the molecule. There are evidences that suggest that antifolates with greater flexibility are more effective against $P$. falciparum strains resistant to PYR and CYC. ${ }^{31}$

WR99210 is the metabolic product of the prodrug known as PS-15. It is an experimental antimalarial that it is even more flexible than MTX and TMP. It is believed that this flexibility is responsible for the exceptional activity of the drug: WR99210 is effective in vitro in concentrations on the nanomolar (nM) range, even against strains that are highly resistant to other DHFR inhibitors. ${ }^{46}$ Unfortunately, preliminary results with this compound showed that its bioavailability in an oral formulation and its phamacokinetical profile were inadequate, thus preventing its direct use in malaria chemotherapy. However, the development of the prodrug PS-15 solved some of the problems related to WR99210, and compounds of this family constitute a source of good perspectives for the creation of new antifolates.

There are several evidences that DHFR inhibitors, in their active forms, have the nitrogen N1 protonated. ${ }^{7,23,31}$ Such protonation is vital, since it makes possible the bidentate hydrogen bonding between the inhibitor and the conserved acidic residue at the active site (Asp 54, in P. falciparum) of DHFR, similarly to the interaction that occurs with the substrate, DHF.

In the remainder of this work, the word antifolate will designate Type 2 antifolates, unless otherwise specified.

\subsection{PfDHFR resistance to antifolates}

Nowadays, antifolates are facing the same problem that has rendered chloroquine nearly useless as antimalarial: the emergence of drug-resistant $P$. falciparum strains. In the beginning of the 1950 's, even before the first chloroquine resistance reports, the first cases of PYRresistance were registered. The combination of PYR with Type- 1 antifolates was an attempt to overcome this problem, but these combinations have also begun to lose their efficacy, so that PS can not be used anymore in South America, Southeast Asia and even in some areas in Africa, where its use is more recent. ${ }^{45,47}$ Cyc-resistance constitutes also a serious problem.

Drug-resistance can be caused by different modifications in the parasite cell. For instance, drug absorption can be reduced by a change in permeability or in the transport properties of the involved membranes. Analogously, the drug elimination rate can be increased, resulting in a lower accumulation in the organism, as it is proposed as the mechanism for chloroquine-resistance. ${ }^{14,45}$
It is also possible that the drug is sequestered or converted into an inactive derivative before it reaches the target. Modifications in the target can also cause pharmacological resistance. In this way, the target protein gene can be amplified several times, resulting in a greater quantity of the protein, which can be excessive for the usual drug dose. The quantity of the target protein in the organism can also increase if its stability is somehow augmented. Finally, it is possible that a gene is mutated, generating a mutant protein with lower drug affinity.

The fast pace at which P. falciparum developed antifolate resistance, either in the field or in the laboratory, suggested that a mutation could be responsible for the loss of efficacy of these pharmaceuticals. ${ }^{45}$ In 1988, just after the determination of the primary structure of pfDHFR, the groups of Cowman and Peterson, working independently, found out that PYR-resistance is related to a mutation at residue 108 , where a serine is substituted by an asparagine..$^{48,49}$ Mutations N51I and C59R were also associated to an increase in PYR-resistance.

In 1990, two other independent studies established basic differences between the mutation patterns responsible for PYR- and CYC-resistance: ${ }^{50,51}$ the double mutation $\mathrm{A} 16 \mathrm{~V}+\mathrm{S} 108 \mathrm{~T}$ originates CYC-resistant strains, which are susceptible to PYR, while the S108N mutation causes PYRresistance, which is increased by mutations N51I and/or C59R. In the same work, Peterson and coworkers identified a strain that is highly resistant to both drugs, which contained a quadruple mutation: N51I + C59R + S108N + I164L. ${ }^{51}$ In 1996, the mutation V140L was identified in Vietnam, together with A16V + S108T, in a strain highly resistant to $\mathrm{CYC} ;{ }^{52}$ however, there are no other studies of this mutation registered in the literature, and its importance to antifolate resistance is unknown. New mutations were found out in Bolivia: C50R and a five-residue insertion (Gly - Lys - Lys - Asn - Glu) between residues Glu-30 and Val-31, denominated as the Bolivia Repeat (BR). ${ }^{43}$ The mutation C50R was detected in areas where PS use is unrestricted, and it increases PYR-resistance thousands of times. On the other hand, although apparently close to the active site of pfDHFR, BR does not seem to affect antifolate-resistance: the only genotype where it has been naturally found (BR/Ile-51/Asn-108/Leu164) is less resistant than the analogous genotype without BR. ${ }^{43,53}$ Research is being conducted to evaluate the real importance of this atypical mutation.

Antifolate-resistance constitutes a serious problem in Brazil, since resistant strains are already disseminated in the country. In the beginning of the 1990's, strains with mutation S108N were predominant in samples collected from infected people in the states of Rondonia, Pará, Mato 
Grosso and Amazonas. ${ }^{54}$ Nearly a decade later, the situation was even worse: samples with different mutations (S108N, N51I, C59R, I164L, C50R and BR) were collected in Porto Velho (RO), Peixoto de Azevedo (MT) and Apiacas (MT). ${ }^{55}$ Chloroquine and PS, the most used antimalarials in Brazil, now have high levels of clinical failure in some areas in the Brazilian Amazon. For instance, in 1987, $92 \%$ of the samples collected in the State of Acre were PS-resistant. Although proguanil has never been officially introduced in Brazil, the existence of a great number of samples with mutation I164L, which causes CYC-resistance, suggests that its use would be ineffective.

Sirawaraporn and coworkers made a kinetic study of several mutant pfDHFR, naturally occurring or not, and proposed a model for the contribution of each mutation to antifolate resistance. ${ }^{56}$ They also proposed an evolutionary tree, reproduced in Figure 11. According to this model, pfDHFR S108N, the only single mutant found in nature, has inhibition constants approximately ten times greater than the wild-type enzyme. Additional mutations in residues 51 and 59 of this mutant generate double mutants N51I+S108N and C59R+S108N, which are 10 to 50 times more resistant to PYR and CYC than the wild-type enzyme. From these mutations, the triple mutants $\mathrm{N} 51 \mathrm{I}+\mathrm{C} 59 \mathrm{R}+\mathrm{S} 108 \mathrm{~N}$ and $\mathrm{C} 59 \mathrm{R}+\mathrm{S} 108 \mathrm{~N}+\mathrm{I} 164 \mathrm{~L}$ are generated; they are 40 to 200 times more resistant than the wild-type pfDHFR. Finally, the quadruple mutant $\mathrm{N} 51 \mathrm{I}+\mathrm{C} 59 \mathrm{R}+\mathrm{S} 108 \mathrm{~N}+\mathrm{I} 164 \mathrm{~L}$ is highly resistant to both drugs.

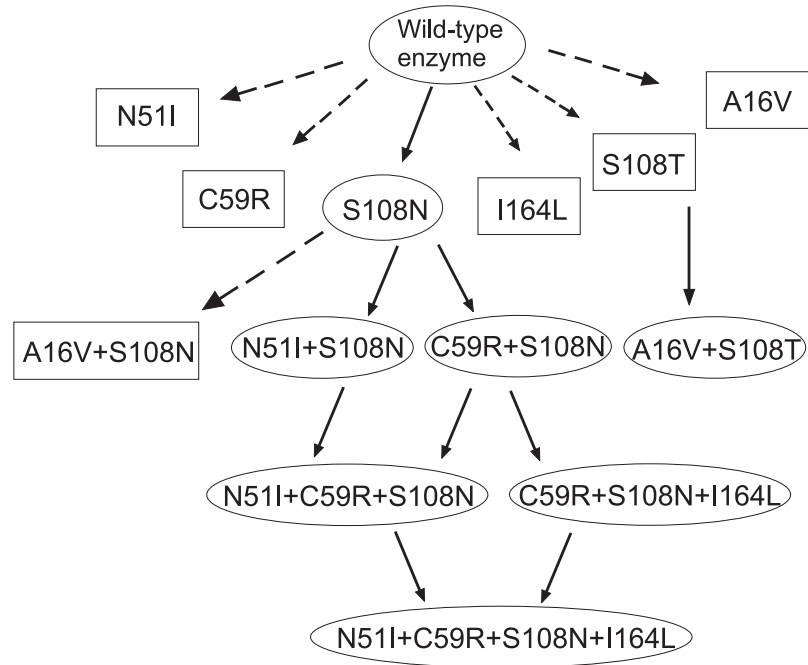

Figure 11. Evolutionary tree for the development of mutations in pfDHFR, proposed by Sirawaraporn and co-workers. ${ }^{56}$ Solid arrows indicate probable trajectories for mutation development, while dashed arrows indicate unlikely trajectories. Ellipse-surrounded mutants are naturally-occurring, and rectangle-surrounded mutants have not been found in nature.
Mutant A16V+S108T cannot have been generated by PYR-pressure, like the mutants described in the previous paragraph; it could not have resisted to PYR, and should have been generated by CYC-pressure. It is worthy of note that the synthetic single mutant $\mathrm{A} 16 \mathrm{~V}$ is highly resistant to $\mathrm{CYC}$, but it is not found in nature, because it also has low activity with $\mathrm{DHF}{ }^{56}$ On the other hand, the synthetic single mutant S108T has no CYC-resistance. For these reasons, Sirawaraporn and coworkers proposed that mutation S108T would have no effect on antifolateresistance, but it would just restore catalytic activity compensating for the A16V mutation. ${ }^{56}$

There are various studies showing unequivocally that antifolate-resistance in pfDHFR, either in the field or in laboratory, is caused by the mutations described. ${ }^{16,17,43,44,53-}$ ${ }^{65}$ An attempt to delay (but not overcome) this problem consists in the use of combinations of two or more drugs to treat malaria, a technique known as combination therapy. Such combinations usually involve a Type 1 and a Type 2 antifolate, such as PS, pyrimethamine-dapsone (commercially known as Maloprim) and chlorproguanildapsone (the first one is the prodrug for the antifolate chlorcycloguanil). ${ }^{47,66}$ However, even these combinations will eventually face the problem of resistance to their action. PS was first used in South America and Southeast Asia in late 1960's, to treat chloroquine-resistant falciparum malaria, but was no longer effective in these areas by the mid-1980's. ${ }^{67}$ In Africa, the extensive use of PS is recent, so that PS-resistance is not widespread yet. However, selection of parasites resistant to its action is already evident, and the exceptional pace of this selection in Asia and South America suggests that PS can become nearly useless also in Africa in a few years, leading to a major health disaster. ${ }^{47}$

Chlorproguanil-dapsone is a potential alternative to PS, because their inexpensive components are eliminated more rapidly than PYR and sulfadoxine, thus reducing the selection pressure; furthermore, this combination is effective even against strains with the N51I+C59R+S108N mutations. ${ }^{6,47}$ Unfortunately, the combination is not effective against strains with the mutation $1164 \mathrm{~L}$, so that its use could select this mutation, rendering the combination useless. ${ }^{6,47}$ The addition of a third drug to chlorproguanil-dapsone is being studied, with artesunate being a promising candidate. ${ }^{47}$

A promising field of research in malaria treatment is the genomics of $P$. falciparum, which has been reviewed elsewhere ${ }^{68}$ but its results will still take some time to be converted to real benefits. In a short term, we believe that the most useful technique to overcome drug resistance is the use of molecular modeling to understand the 
mechanisms by which the mutations confer drug resistance. This knowledge would lead to the design of antifolates which could be simultaneously active against wild-type and mutant pfDHFR strains and less susceptible to drug resistance.

\subsection{Proposed mechanisms for antifolate-resistance}

Due to the fact that the tertiary structure of pfDHFR-TS has not been determined experimentally so far (not even for the pfDHFR domain), homology models were constructed in an attempt to get information about the enzyme structure and its functional properties. These models allow even the simulation of the interactions among the enzyme, the coenzyme and the substrate (or the inhibitor), by the use of docking techniques. ${ }^{69}$ The application of these procedures has resulted in theoretical models of pfDHFR bound to some drugs, which made possible the proposal of some mechanisms for antifolate resistance.

The first published pfDHFR theoretical model was the one of Lemcke and coworkers, ${ }^{40}$ which used human DHFR as template. They proposed that mutation S108N would set residue Asn-108 too close to the chlorine atom of PYR, in such a way that there might not be enough space for this drug to bind to the enzyme. The effect of mutations N51I and C59R could not be explained by this model, though the authors have raised the possibility that these residues might have an indirect influence on the steric or electrostatic properties of the binding site. Mutations I164L, S108T and A16V were not discussed in this work.

The model of Rastelli and coworkers was created from the multiple alignment of pfDHFR primary structure with sequences of several DHFR whose tertiary structures had been determined crystallographically. ${ }^{7}$ Mutations A16V and S108T (single and crossed) were studied in this work. Based on this model, Rastelli's group proposed that the high resistance of mutant $\mathrm{A} 16 \mathrm{~V}+\mathrm{S} 108 \mathrm{~T}$ to $\mathrm{CYC}$ would result from a displacement of the drug in the active site, due to a steric clash between residue Val-16 and one of the methyl groups of CYC. They also proposed that the absence of an analogous clash in PYR and WR99210 would be the reason for the lack of resistance of mutant A16V+S108T to these drugs.

Santos-Filho and co-workers created a pfDHFR homology model using chicken liver DHFR as template. ${ }^{36,42}$ They also modeled the quadruple mutant $\mathrm{N} 51 \mathrm{I}+\mathrm{C} 59 \mathrm{R}+\mathrm{S} 108 \mathrm{~N}+\mathrm{I} 164 \mathrm{~L}$, and analyzed the influence of these mutations on antifolate resistance. According to their model, mutation S108N could cause some hindrance to the dynamical process of admission and accommodation of the inhibitors to the active site, a similar theory to that proposed by Lemcke's workgroup. Mutation I164L would result in a change of the active site shape, since the leucine sidechain is bulkier and wider than the isoleucine sidechain. The role of mutations N51I and C59R is not clear in this model, but the authors have suggested that the influence of the latter would be consequence of a repulsion between the positively charged Arg-59 and the drug, which interacts in a protonated form, as already mentioned.

None of these works presented an extensive work of mutant pfDHFRs, limiting themselves to the analysis of just some mutations. For this reason, we have recently proposed a new model for wild-type pfDHFR, ${ }^{41}$ based on a refinement of the model of Santos-Filho et al. ${ }^{36,42}$ In that work we also modeled fourteen mutants, in an attempt to identify pharmacodynamic differences between them and the wild-type enzyme, and to evaluate possible synergy effects between two or more mutations. It was concluded that S108N and A16V are the key mutations for PYR- and CYC-resistance, respectively, as previously proposed by Sirawaraporn. ${ }^{56}$ The former acts by displacing the drug from its original position, due to a steric clash between Asn-108 and the chlorine atom of PYR, resulting in a loss of planarity of the bidentate hydrogen bond of the drug with Asp-54, thus leading to destabilization of the ternary complex. The resistance mechanism of mutation A16V is not clear, since the comparison of our results with those of Rastelli's group shows different results., ${ }^{7,41}$ In this way, either Rastelli's hypothesis is correct, and A16V acts by displacing CYC form its position, due to a steric clash between Val-16 and one of the methyl group of the drug, or our hypothesis is right, and $\mathrm{A} 16 \mathrm{~V}$ acts by causing a rotation of Asp-54 carboxylate group, due to a steric clash between Val-16 and Asp-54, resulting in a loss of planarity of the bidentate bond. If this last hypothesis were correct, then, for some unknown reason, CYC would be more sensitive to the loss of planarity of the bidentate bond than PYR. This would explain why the mutants A16V and $\mathrm{A} 16 \mathrm{~V}+\mathrm{S} 108 \mathrm{~T}$ are highly resistant to the former and sensitive to the latter. The action of mutations N51I and C59R cannot be understood from our model, but the distances between these residues and the drug position in the active site suggest that their action would be primarily on the approximation of the drug to the active site, rather than on its accommodation; this effect should be of electrostatic nature and should be relevant only when it is associated to mutation S108N, amplifying its effect, in agreement with the observations of Sirawaraporn's group. ${ }^{56}$ Our model proposed a theory for the action of mutation I164L when isolated, as in the artificial mutant I164L, but 
not for its action in triple and quadruple mutants. Finally, the role of the mutation S108T is not clear in our model, but it seems that it has no effect on antifolate resistance; its finality would be just to restore, in a way yet to be determined, catalytic activity to mutant A16V, as previously proposed. ${ }^{56}$

\section{Conclusion}

Malaria is still a serious health problem in the world, and very few advances have been made recently on its chemotherapy. Currently used antifolates are rapidly losing their efficiency against $P$. falciparum. If they are not replaced by new ones, which must be effective against wild type and mutant strains of Plasmodium, the consequences will be catastrophic, mainly in Tropical Africa.

Since the experimental pfDHFR tertiary structure has not been determined yet, the research on new antifolates relies mainly on molecular modeling procedures. There are few groups applying these techniques to the research of malaria chemotherapy all over the world, and we expect that a whole new classes of antifolates will eventually be available for human use as the combined result of these efforts.

\section{Acknowledgements}

We are grateful to the Brazilian agencies $\mathrm{CNPq}$ and FAPERJ, for financial support.

\section{References}

1. Foye, W. O. In Principles of Medicinal Chemistry; Foye, W. O., Lemke, T. L., Williams, D. A., eds.; Williams \& Wilkins: Philadelphia, 1995, ch. 32.

2. McKie, J. H.; Drug Des. Discovery. 1994, 11, 269.

3. http://www.wehi.edu.au/MalDB-www/intro.html, accessed in October 2002.

4. http://www.who.int/inf-fs/en/InformationSheet01.pdf, accessed in October 2002.

5. Macreadie, I.; Ginsburg, H.; Sirawaraporn, W.; Tilley, L.; Parasitol. Today 2000, 16, 438.

6. Winstanley, P. A.; Parasitol. Today 2000, 16, 146.

7. Rastelli, G.; Sirawaraporn, W.; Sompornpisut, P.; Vilaivan, T.; Kamchonwongpaisan, S.; Quarrel, R.; Lowe, G.; Thebtaranonth, Y.; Yuthavong, Y.; Bioorg. Med. Chem. 2000, 8, 1117.

8. Rosa-Freitas, M. G.; Lourenço-de-Oliveira, R.; Carvalho-Pinto, C. J.; Flores-Mendonza, C.; Silva-do-Nascimento, T. F.; Mem. I. Oswaldo Cruz 1998, 93, 651.
9. Tadei, W. P.; Thatcher, B. D.; Santos, J. M. M.; Scarpassa, V. M.; Rodrigues, I. B.; Rafael, M. S.; Am. J. Trop. Med. Hyg. 1998, 59, 325.

10. Marques, A. C.; Rev. Soc. Bras. Med. Trop. 1995, 28, 141.

11. Soares, I. S.; Rodrigues, M. M.; Braz. J. Med. Biol. Res. 1998, $31,317$.

12. Good, M. F.; Kaslow, D. C.; Miller, L. H.; Annu. Rev. Immunol. 1998, 16, 57.

13. Holder, A. A.; Proc. Natl. Acad. Sci. USA 1999, 96, 1167.

14. Olliaro, P.; Pharmacol. Ther. 2001, 89, 207.

15. Peters, W.; Adv. Parasitol. 1998, 41, 1.

16. Urdaneta, L.; Plowe, C.; Goldman, I.; Lal, A. A.; Am. J. Trop. Med. Hyg. 1999, 61, 457.

17. Toteja, R.; Nair, L.; Bhasin, V. K.; Mem. I. Oswaldo Cruz 2001, 96, 427.

18. White, N. J.; J. Antimicrob. Chemother. 1992, 30, 571.

19. Zalis, M. G.; Pang, L.; Silveira, M. S.; Milhous, W. K.; Wirth, D. F.; Am. J. Trop. Med. Hyg. 1998, 58, 630.

20. Adagu, I. S.; Warhurst, D. C.; Ogala, W. N.; Abdaguye, I.; Audu, L. I.; Bamgbola, F. O.; Ovwigho, U. B.; Trans. R. Soc. Trop. Med. Hyg. 1995, 89, 422.

21. http://www.funasa.gov.br (window "Guia de Doenças"), accessed in October 2002.

22. Liu, D.; Liu, R.; Zhang, C.; Cai, X.; Tang, X.; Yang, H.; Yang, P; Dong, Y; Chin. J. Parasitol. Parasitic Dis. 1996, 14, 37.

23. Kraut, J.; Matthews, D. A.; In Biological Macromolecules and Assemblies; Jurnak, F. A.; McPherson, A., eds.; John Wiley \& Sons Ltd.: New York, USA, 1987, vol. 3, ch. 1.

24. Stryer, L.; Bioquímica, $4^{\text {th }}$ ed., Editora Guanabara Koogan S.A.: Rio de Janeiro, 1995.

25. Birdsall, B.; Feeney, J.; Tendler, S. J. B.; Hammond, S. J.; Roberts, G. C. K.; Biochemistry 1989, 28, 2297.

26. Zuccotto, F.; Martin, A. C. R.; Laskowski, R. A.; Thornton, J. M.; Gilbert, I. H.; J. Comput.-Aided Mol. Des. 1998, 12, 241.

27. Sirawaraporn, W.; Drug Res. Updates 1998, 1, 397.

28. Costi, M. P.; Ferrari, S.; Curr. Drug Targets 2001, 2, 135.

29. Berman, H. M.; Westbrook, J.; Feng, Z.; Gilliland, G.; Bhat, T. N.; Weissig, H.; Shindyalov, I. N.; Bourne, P. E.; Nucleic Acids Res. 2000, 28, 235.

30. Bzik, D. J.; Li, W.-B.; Horii, T.; Inselburg, J.; Proc. Natl. Acad. Sci. USA 1987, 84, 8360.

31. Warhurst, D. C.; Drug Disc. Today 1998, 3, 538.

32. Cummins, P. L.; Gready, J. E.; J. Am. Chem. Soc. 2001, 123, 3418 .

33. Bystroff, C.; Oatley, S. J.; Kraut, J.; Biochemistry 1990, 29, 3263.

34. Casarotto, M. G.; Basran, J.; Badii, R.; Sze, K. H.; Roberts, G. C. K.; Biochemistry 1999, 38, 8038.

35. Olliaro, P.; Yuthavong, Y.; Pharmacol. Ther. 1999, 81, 91.

36. Santos-Filho, O. A.; de Alencastro, R. B.; Figueroa-Villar, J. D.; Biophys. Chem. 2001, 91, 305. 
37. Johnson, M. S.; Srinivasan, N.; Sowdhamini, R.; Blundell, T. L.; Crit. Rev. Biochem. Mol. Biol. 1994, $29,1$.

38. Höltje, H.-D.; Folkers, G.; In Methods and Principles in Medicinal Chemistry; Mannhold, R.; Kubinyi, H.; Timmerman, H., eds.; VCH Verlagsgesellschaft mbH: Weinheim: Federal Republic of Germany, 1997.

39. Martí-Renom, M. A.; Stuart, A. C.; Fiser, A.; Sánchez, R.; Melo, F.; Sali, A.; Annu. Rev. Biophys. Biomol. Struct. 2000, 29, 291.

40. Lemcke, T.; Christensen, I. T.; Jfrgensen, F. S.; Bioorg. Med. Chem. 1999, 7, 1003.

41. Delfino, R. T.; Santos-Filho, O. A.; Figueroa-Villar, J. D.; Biophys. Chem. 2002, 98, 287.

42. Santos-Filho, O. A.; PhD Thesis, Instituto Militar de Engenharia, Brazil, 2000.

43. Plowe, C. V.; Cortese, J. F.; Djimde, A.; Nwanyanwu, O. C.; Watkins, W. M.; Winstanley, P. A.; Estrada-Franco, J. G.; Mollinedo, R. E.; Avila, J. C.; Cespedes, J. L.; Carter, D.; Doumbo, O. K.; J. Infect. Dis. 1997, 176, 1590.

44. Nzila, A. M.; Mberu, E. K.; Sulo, J.; Dayo, H.; Winstanley, P. A.; Sibley, C. H.; Watkins, W. M.; Antimicrob. Agents Chemother. 2000, 44, 991.

45. Hyde, J. E.; Pharmacol. Ther. 1990, 48, 45.

46. Ferlan, J. T.; Mookherjee, S.; Okezie, I. N.; Fulgence, L.; Sibley, C. H; Mol. Biochem. Parasitol. 2001, 113, 139.

47. Sibley, C. H.; Hyde, J. E.; Sims, P. F. G.; Plowe, C. V.; Kublin, J. G.; Mberu, E. K.; Cowman, A. F.; Winstanley, P. A.; Watkins, W. M.; Nzila, A. M.; Trends Parasitol. 2001, 17, 582.

48. Cowman, A. F.; Morry, M. J.; Biggs, B. A.; Cross, G. A. M.; Foote, S. J.; Proc. Natl. Acad. Sci. USA 1988, 85, 9109.

49. Peterson, D. S.; Walliker, D.; Wellems, T. E.; Proc. Natl. Acad. Sci. USA 1988, 85, 9114.

50. Foote, S. J.; Galatis, D.; Cowman, A. F. Proc. Natl. Acad. Sci. USA 1990, 87, 3014.

51. Peterson, D. S.; Milhous, W. K.; Wellems, T. E; Proc. Natl. Acad. Sci. USA 1990, 87, 3018.

52. Zindrou, S.; Dung, N. P.; Sy, N. D.; Sköld, O.; Swedberg, G.; Exp. Parasitol. 1996, 84, 56.

53. Cortese, J. F.; Plowe, C. V.; Mol. Biochem. Parasitol. 1998, 94 , 205.
54. Peterson, D. S.; Di Santi, S. M.; Povoa, M.; Calvosa, V. S.; Do Rosario, V. E.; Wellems, T. E.; Am. J. Trop. Med. Hyg. 1991, $45,492$.

55. Vasconcelos, K. F.; Plowe, C. V.; Fontes, C. J.; Kyle, D.; Wirth, D. F.; Pereira da Silva, L. H.; Zalis, M. G.; Mem. I. Oswaldo Cruz, 2000, 95, 721.

56. Sirawaraporn, W.; Sathitkul, T.; Sirawaraporn, R.; Yuthavong, Y.; Santi, D. V.; Proc. Natl. Acad. Sci. USA 1997, 94, 1124.

57. Sirawaraporn, W.; Yongkiettrakul, S.; Sirawaraporn, R.; Yuthavong, Y.; Santi, D. V.; Exp. Parasitol. 1997, 87, 245.

58. Thaithong, S.; Chan, S.-W.; Songsomboon, S.; Wilairat, P.; Seesod, N.; Sueblinwong, T.; Goman, M.; Ridley, R.; Beale, G.; Mol. Biochem. Parasitol. 1992, 52, 149.

59. Jelinek, T.; Rfnn, A. M.; Lemnge, M. M.; Curtis, J.; Mhina, J.; Duraisingh, M. T.; Bygbjerg, I. C.; Warhurst, D. C.; Trop. Med. Int. Health 1998, 3, 605.

60. Diourté, Y.; Djimdé, A.; Doumbo, O. K.; Sagara, I.; Coulibaly, Y.; Dicko, A.; Diallo, M.; Diakité, M.; Cortese, J. F.; Plowe, C. V.; Am. J. Trop. Med. Hyg. 1999, 60, 475.

61. Basco, L. K.; Ringwald, P.; Am. J. Trop. Med. Hyg. 2000, 62, 271.

62. Nzila, A. M.; Nduati, E.; Mberu, E. K.; Sibley, C. H.; Monks, S. A.; Winstanley, P. A.; Watkins, W. M.; J. Infect. Dis. 2000, 181, 2023.

63. Biswas, S.; Escalante, A.; Chaiyaroj, S.; Angkasekwinai, P.; Lal, A. A.; Trop. Med. Int. Health 2000, 5(10), 737.

64. Mawili-Mboumba, D.-P.; Ekala, M.-T.; Lekolou, F.; Ntoumi, F.; Acta Tropica 2001, 78, 231.

65. Brobey, R.K.B.; Iwakura, M.; Itoh, F.; Aso, K.; Horii, T.; Parasitol. Int. 1998, 47, 69.

66. McKie, J. H.; Douglas, K. T.; Chan, C.; Roser, S. A.; Yates, R.; Read, M.; Hyde, J. E.; Dascombe, M. J.; Yuthavong, Y.; Sirawaraporn, W.; J. Med. Chem. 1998, 41, 1367.

67. Watkins, W. M.; Mberu, E. K.; Winstanley, P. A.; Plowe, C. V.; Parasitol. Today 1997, 13, 459.

68. Cowman, A. F.; Int. J. Parasitol. 2001, 31, 871.

69. Lambert,M. H. In Practical Application of Computer-Aided Drug Design. Charifson, P. S., eds.; Marcel Dekker Inc.: New York, 1997, ch. 8. 